\title{
Correction to: EEMD-based online milling chatter detection by fractal dimension and power spectral entropy
}

\author{
Yongjian $\mathrm{Ji}^{1} \cdot$ Xibin Wang $^{1} \cdot$ Zhibing Liu $^{1} \cdot$ Zhenghu Yan $^{1} \cdot$ Li Jiao $^{1} \cdot$ Dongqian Wang ${ }^{1} \cdot$ Junqing Wang ${ }^{1}$ \\ Published online: 20 October 2020 \\ (C) Springer-Verlag London Ltd., part of Springer Nature 2020
}

Correction to: The International Journal of Advanced

Manufacturing Technology (2017) 92: 1185-1200

https://doi.org/10.1007/s00170-017-0183-7

The original version of this article contained mistakes.

1. In Fig. $7 \mathrm{~b}$ and Fig. $7 \mathrm{c}$, the data after $3.9 \mathrm{~s}$ are redundant. These errors are caused by mistakenly importing the same data segment during the process of plotting these two figures. The correct images of Fig. $7 \mathrm{~b}$ and Fig. $7 \mathrm{c}$ are shown below.

2. In the schematic diagram of Fig. 14, the number of cutter teeth is 3 , and the axial depth of cut is $a_{\mathrm{p}}=4 \mathrm{~mm}$. The correct image is shown below.

The online version of the original article can be found at https://doi.org/ $10.1007 / \mathrm{s} 00170-017-0183-7$

Zhibing Liu

liuzhibing@bit.edu.cn

Yongjian Ji

yongiian8701@163.com

1 Key Laboratory of Fundamental Science for Advanced Machining, Beijing Institute of Technology, No.5 South Zhongguancun Street, Haidian District, Beijing 100081, People's Republic of China 
Fig. 7 The acceleration signals of different milling states. $\mathbf{b}$

Condition B. c Condition C
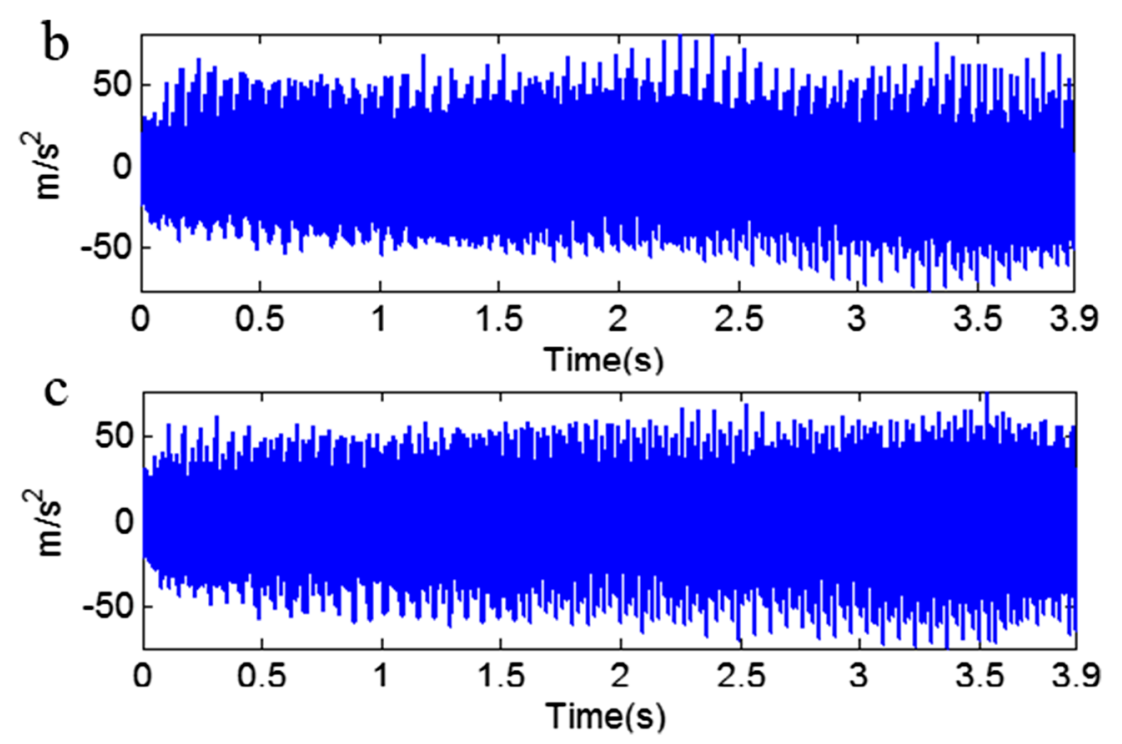

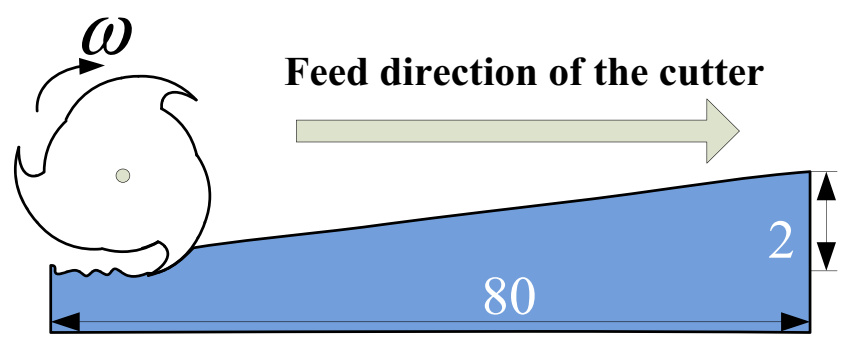

Fig. 14 The milling state diagrams (top view, $a_{\mathrm{p}}=4 \mathrm{~mm}$ )

Publisher's note Springer Nature remains neutral with regard to jurisdictional claims in published maps and institutional affiliations. 